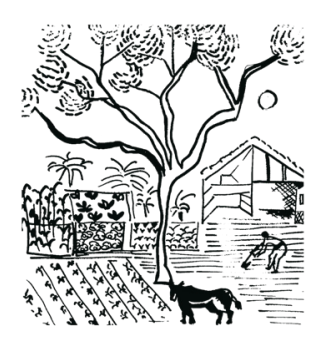

Vol. 22 N.2 de 2019 ISSN: 1516-8182

Recebimento: 10/01/2019

Aceite: 01/04/2019

DOI: 10.25059/2527-2594/retratosdeassentamentos/2019.v22i2.336

\title{
Saneamento rural e percepção ambiental em um assentamento rural - São Paulo - Brasil
}

\author{
Danitielle Cineli Simonato ${ }^{1}$ \\ Rodolfo Antônio de Figueiredo ${ }^{2}$ \\ Carolina Buso Dornfeld ${ }^{3}$ \\ Vanilde Ferreira de Souza Esquerdo ${ }^{4}$ \\ Sonia Maria Pessoa Pereira Bergamasco ${ }^{5}$
}

ReSumo: O saneamento no meio rural anos é um desafio em relação à promoção da saúde e da qualidade de vida. O objetivo deste estudo foi analisar as questões referentes ao saneamento básico (abastecimento de água, coleta de esgoto e de resíduos sólidos) e a percepção ambiental de assentados rurais do Assentamento Estrela da Ilha - Ilha Solteira - São Paulo. O estudo teve abordagem quantitativa e qualitativa, os instrumentos de pesquisa utilizados foram o questionário semiestruturado e o diário de campo. De modo geral, os resultados revelaram que a questão do abastecimento de água, a construção de poços, a qualidade da água era preocupante. O esgoto sanitário, embora incipiente, se encontra latente, no que diz respeito, ao percentual de fossas sépticas no assentamento. A gestão dos resíduos sólidos foi outro problema encontrado, já que a maioria dos assentados utiliza da incineração ou enterro dos resíduos. Notamos que os assentados percebem estes problemas nos seus lotes e no assentamento como um todo e que uma importante solução seria criar um programa de educação ambiental, a coleta seletiva e melhoria do serviço de assistência técnica e extensão rural - ATER no que tange a esta temática.

Palavras-Chave: Qualidade de Vida; Reforma Agrária; Saneamento Básico; Saúde Pública.

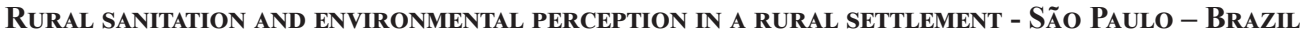

ABSTRACT: Sanitation in rural years is a challenge in relation to the promotion of health and quality of life. The aim of this study was to analyze the issues related to basic sanitation (water supply, sewage collection and solid waste) and the environmental perception of rural settlers from the Estrela da Ilha Settlement - Ilha Solteira - São Paulo. The study had a quantitative and qualitative approach, the research instruments used

\footnotetext{
${ }^{1}$ Doutoranda na Faculdade de Engenharia Agrícola (FEAGRI) na Universidade Estadual de Campinas (UNICAMP). E-mail: dani_simonato@yahoo.com.br

2 Professor Associado do Departamento de Ciências Ambientais do Centro de Ciências Biológicas e da Saúde (DCAm/ CCBS) e credenciado no Programa de Pós-Graduação em Ciências Ambientais (PPGCAm/UFSCar).E-mail: rodolfodcam@ gmail.com

${ }^{3}$ Professora Doutora na Universidade Estadual Paulista - Júlio de Mesquita Filho, Câmpus de Ilha Solteira (SP).E-mail: caroldornfeld@gmail.com

${ }^{4}$ Professora Doutora - Faculdade de Engenharia Agrícola - Universidade Estadual de Campinas - Feagri/Unicamp.E-mail: vanilde.esquerdo@feagri.unicamp.br

${ }^{5}$ Professora Titular - Faculdade de Engenharia Agrícola - Universidade Estadual de Campinas - Feagri/Unicamp. E-mail: soniaberga@yahoo.com
} 
were the semi-structured questionnaire and the field diary. In general, the results revealed that the issue of water supply, the construction of wells, the quality of water was worrying. The sewage, although incipient, is latent, with regard to, the percentage of septic pits in the settlement. Solid waste management was another problem encountered, since most settlers use waste incineration or burial. We note that the settlers perceive these problems in their lots and in the settlement as a whole and that an important solution would be to create an environmental education program, selective collection and improvement of technical assistance and rural extension service - ATER in what this theme.

KeYwords: Quality of Life; Land Reform; Basic Sanitation; Public Health.

\section{INTRODUÇÃ̃o}

Este artigo teve por objetivo analisar as questões referentes ao saneamento básico (abastecimento de água, coleta de esgoto e de resíduos sólidos) e a percepção ambiental de assentados rurais do Assentamento Estrela da Ilha - Ilha Solteira - São Paulo. As justificativas que nortearam o estudo estão relacionadas com a compreensão do espaço rural como um espaço de vida, de trabalho e de moradia e que demanda políticas públicas e ações diferenciadas para garantir a qualidade de vida e o bem estar da população.

O saneamento básico é uma ação pública essencial e de suma importância para garantir a qualidade de vida das pessoas, a promoção da saúde e salubridade e sustentabilidade ambiental. A população rural brasileira, segundo dados do Instituto Brasileiro de Geografia e Estatística IBGE (2010), compreende cerca de 30 milhões de pessoas, representando $16 \%$ da população total. A população rural brasileira é altamente diversificada e apresenta categorias como: agricultores patronais, agricultores familiares tradicionais, quilombolas, indígenas, assentados rurais, entre outros.

Especificamente, neste estudo, trabalhamos com assentados e assentadas rurais, estes por sua vez, vislumbraram na luta pela terra uma chance de vida e de trabalho. Os assentamentos rurais se configuram como:

Novas unidades de produção agrícola, gerados pelo surgimento de novas formas de organização, por meio de políticas governamentais visando o reordenamento do uso da terra em benefício de trabalhadores rurais sem terra ou com pouca terra (BERGAMASCO; NORDER, 1996 7-8p).

Diante da diversidade cultural, identitária, econômica, social, política e 
ambiental, a universalização do saneamento ambiental rural se torna um desafio. Para além disso, historicamente, o serviço de saneamento em áreas rurais sempre se mostrou ineficiente, escasso e até inexistente, devido a fatores como: falta de investimento público, longas distâncias, o isolamento das comunidades, a falta de investimento para o desenvolvimento de tecnologias de baixo custo, além de vontade política para atender esse contingente populacional.

Em termos conceituais, o serviço de saneamento ambiental rural compreende serviços como: abastecimento de água, esgotamento sanitário e gestão de resíduos sólidos e se define como:

"Conjunto de ações socioeconômicas que têm por objetivo alcançar a salubridade ambiental, por meio de abastecimento de água potável, coleta e disposição sanitária de resíduos sólidos, líquidos e gasosos, promoção da disciplina sanitária de uso do solo, drenagem urbana, controle de doenças transmissíveis e demais serviços e obras especializadas, com a finalidade de proteger e melhorar as condições de vida urbana e rural"(BRASIL, 2004, p.21).

O principal aparato legislativo do saneamento no Brasil se dá pela lei $\mathrm{n}^{\mathrm{o}} 11.445 / 2007$ que estabelece as diretrizes nacionais para o saneamento básico:

Entre as diretrizes (artigo 48), destaca-se:

VII - garantia de meios adequados para o atendimento da população rural dispersa, inclusive mediante a utilização de soluções compatíveis com suas características econômicas e sociais peculiares

Entre os objetivos (art. 49), destaca-se:

IV - proporcionar condições adequadas de salubridade ambiental às populações rurais e de pequenos núcleos urbanos isolados (BRASIL, 2007).

A falta de um serviço de saneamento básico no meio rural aumenta significativamente as desigualdades sociais e a pobreza no meio rural. Dados do relatório "Progress on Drinking Water, Sanitation and Hygiene: Update and Sustainable Development Goal baselines, edição de 2017 idealizados pelo World Health Organization (WHO) e United Nations Children's Fund (UNICEF) revelam a situação do saneamento básico e o acesso à água no mundo relatam que as redes de esgoto são predominantes em áreas urbanas cobrindo dois terços da população (63\%). Em áreas rurais esta cobertura não ultrapassa $9 \%$ da população. O mesmo 
acontece quando falamos sobre o consumo e utilização de águas superficiais não tratadas para o consumo humano, das 161 milhões de pessoas que fazem uso destas águas, 150 milhões vivem em áreas rurais.

O cenário brasileiro, sobretudo o cenário rural, também não é muito diferente, dados do Sistema Nacional de Informação sobre Saneamento (SNIS) de 2017, afirmam que $16,6 \%$ da população não têm acesso à água e 47,6\% não têm coleta de esgoto. Nas áreas rurais, dados da Pesquisa Nacional por Amostra de Domicílio (PNAD) do ano de 2014, reforçam que apenas 33,41\% do abastecimento de água está ligado à rede, no restante dos domicílios o abastecimento de água é proveniente de outras fontes como poços diversos, rios, reservatórios e etc. Em se tratando de esgotamento sanitário no meio rural, 49,9\% dos domicílios apresentam como forma de esgotamento sanitário a fossa rudimentar, seguidos por 23,5\% com fossa séptica, outros $18,7 \%$ com outras soluções e apenas 7,8\% ligados à rede coletora. Já em relação a coleta de resíduos sólidos dos domicílios rurais, 64,8\% dos resíduos sólidos têm destino diverso, outros $27 \%$ dos domicílios têm coleta direta, seguidos por $8,2 \%$ com coleta indireta (SNIS, 2017; PNAD, 2014).

Especificamente, em se tratando de assentamentos rurais e sua implementação, a instrução normativa Instituto de Colonização e Reforma Agrária (INCRA) n ${ }^{\circ} 15$ de 30/03/2004 no seu artigo $2^{\circ}$, define que o INCRA deverá:

I - garantir a efetiva participação dos assentamentos nas atividades de planejamento e execução das ações relativas ao desenvolvimento territorial; II - aportar os recursos orçamentários e financeiros preferencialmente de forma global e não fragmentada; III - garantir a Assessoria Técnica, Social e Ambiental desde o início da Implantação do Assentamento, de forma a definir o modelo de exploração da área, organização espacial, moradia, infraestrutura básica, licenciamento ambiental e serviços sociais; IV qualificar e adequar as normas ambientais como ação e condição necessária à implantação do Plano de Desenvolvimento do Assentamento - PDA, promovendo a exploração racional e sustentável da área e a melhoria de qualidade de vida dos assentados; $\mathrm{V}$ - fortalecer o processo de constituição da capacidade organizativa, com base na cooperação e no associativismo das famílias assentadas; VI - articular e integrar as políticas públicas de assistência técnica, extensão rural, educação, saúde, cultura, eletrificação rural, saneamento básico, necessárias ao desenvolvimento do projeto de assentamento; VII - possibilitar que as áreas reformadas sejam indutoras do Desenvolvimento Territorial combatendo as causas da fome e da pobreza.

Procurar conhecer e compreender a realidade do saneamento básico em áreas 
rurais, sobretudo em assentamentos rurais que foram espaços criados visando um reordenamento fundiário, um espaço de vida, trabalho e melhores condições de vida que o se torna importante.

\section{CAMinhos METOdológicos}

\section{LOCAL DE ESTUDO}

A pesquisa foi realizada com as famílias do assentamento Estrela da Ilha, localizado no município de Ilha Solteira - SP (Figura 1). O assentamento foi criado em setembro de 2005, após luta e mobilização de quatro núcleos de acampamentos do Movimento dos Trabalhadores Rurais Sem Terra (MST) pela antiga fazenda São José da Barra, que foi desapropriada para fins de reforma agrária.

O assentamento possui uma área de 2.964,3356 hectares, composta por 186 lotes de cerca de 14 hectares cada um e 23 lotes de cerca de 3,5 hectares cada (lotes denominados pararrurais: destinados a solteiros), totalizando 209 lotes (Figura 1).

Figura 1 - Localização do Assentamento Estrela da Ilha - Área Rural do Município de Ilha Solteira (SP). Escala $2 \mathrm{~km}$.

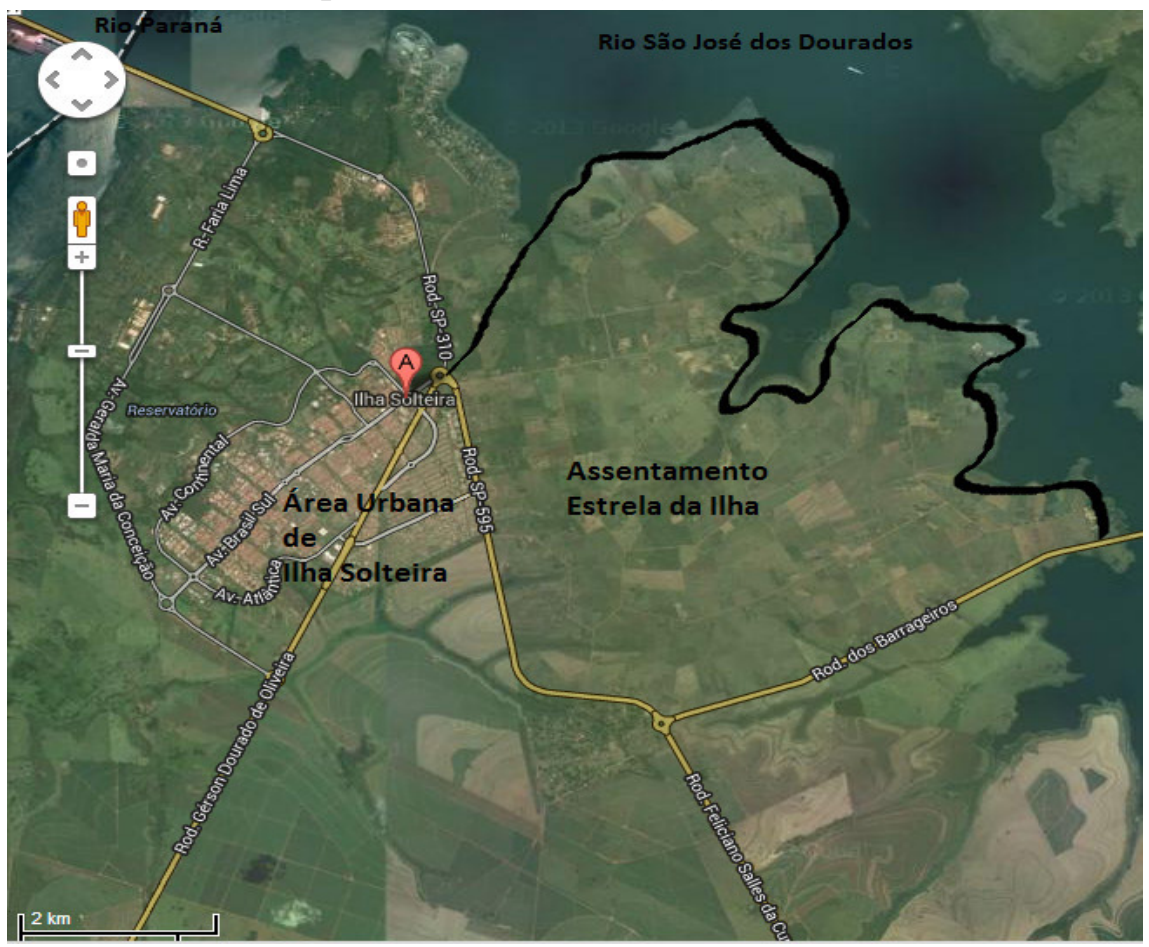

Fonte: Google Maps. 


\section{Descrição dos Procedimentos Metodológicos}

A pesquisa foi realizada com 35 famílias, cerca de $20 \%$ de famílias do assentamento no ano de 2013. Primeiramente foi apresentada a temática da pesquisa com as quatro lideranças do assentamento e suas respectivas famílias, essas lideranças eram os chefes das associações de produtores. Na sequência foi solicitado para que essas lideranças indicassem outras famílias para fazermos a pesquisa e assim, sucessivamente. Esse é um tipo de amostragem não probabilística de pesquisa denominada "bola de neve" do inglês "snow ball sampling". Esta técnica consiste nos participantes iniciais de um estudo indicarem novos participantes que, por sua vez, indicam novos participantes e assim sucessivamente, até que seja alcançado o objetivo proposto (o "ponto de saturação").

O "ponto de saturação" é atingido quando os novos entrevistados passam a repetir os conteúdos já obtidos em entrevistas anteriores, sem acrescentar novas informações relevantes à pesquisa. Portanto, a snowball ("Bola de Neve") é uma técnica de amostragem que utiliza cadeias de referência, uma espécie de rede (BIERNACKI; WALDORF, 1981).

Levando em consideração a relação da amostragem, o instrumento de pesquisa utilizado para atingirmos o objetivo da pesquisa foi o questionário semiestruturado, este continha 50 questões abertas e fechadas divididas em oito blocos que versavam sobre o perfil social, econômico e ambiental dos assentados. Porém, neste artigo daremos ênfase aos aspectos ambientais que foram o saneamento ambiental, a questão dos resíduos sólidos e a percepção ambiental dos assentados.

De acordo com Gil (2005), o questionário é uma técnica de pesquisa das mais utilizadas consistindo em um instrumento de coleta de informações que apresenta muitas vantagens, pois possibilita de forma rápida o conhecimento de opiniões, crenças, sentimentos, interesses, expectativas, situações vivenciadas, entre outras.

Para a análise de dados optou-se pela abordagem quantitativa e qualitativa que, para Minayo (2005), tem por objetivo dimensionar e quantificar dados de determinado processo e resultados. As abordagens qualitativas visam aprofundar o estudo, dentro de um contexto histórico e de uma dinâmica relacionada hierárquica, entre pares ou com a população, e compreender as representantes e os sinais evasivos que não podem ser entendidos por meios formais.

Foi utilizado o diário de campo como instrumento de registro de informações, onde procuramos registrar os momentos relevantes da pesquisa como falas, sentimentos, observações, relatos informações, a fim de ilustrar de modo mais fidedigno a história da comunidade e dos próprios indivíduos, enfatizando a percepção ambiental dos mesmos frente a problemática do saneamento rural. 
Ademais, para a realização deste estudo, o mesmo foi submetido ao Comitê de Ética em Pesquisas em Seres Humanos da Universidade Federal de São Carlos (UFSCar) (Parecer $n^{\circ}$ 030/2012), as informações foram coletadas mediante assinatura do Termo de Consentimento Livre e Esclarecido (TCLE).

\section{Resultados E discussão \\ Perfil dos Assentados Pesquisados}

Para ilustrarmos nossos entrevistados traremos um breve perfil dos mesmos. Com relação ao gênero, $60 \%$ dos assentados eram do sexo masculino, quanto ao estado civil $94 \%$ eram casados. Com relação a faixa etária $37 \%$ dos assentados estavam na faixa de 40 a 50 anos de idade, a média de idade ficou em torno de 47 anos. Além disso, $51 \%$ dos entrevistados possuíam renda média de dois salários mínimos por mês, seguidos por $26 \%$ que possuíam renda equivalente a um salário mínimo mensal. Quanto a escolaridade 68\% dos entrevistados possuíam o Ensino Fundamental Completo.

\section{A questão da Água no Assentamento Estrela da IlHa}

Em relação ao abastecimento de água nos lotes, 94\% dos lotes eram abastecidos por poços individuais (sendo estes do tipo caipira, semi-artesiano ou artesiano), outros $6 \%$ dos lotes eram abastecidos por poços comunitários construídos pelo INCRA.

Relatos durante a pesquisa de campo denotam que dos oito poços construídos em 2005, apenas três estavam funcionando adequadamente na época devido à falta de manutenção por parte do INCRA.

Além do mau funcionamento dos poços comunitários, deixando muitas famílias com abastecimento de água comprometido, a de falta d'água em meses de estiagem vem sendo um problema sério e que se agrava a cada ano, sendo os meses de abril a novembro os mais críticos.

Sobre a questão de falta d'água em longo período do ano, estudos de Hernandez et al. (2003) indicam que a bacia hidrográfica do Rio São José dos Dourados, na qual o assentamento está localizado, pode apresentar conflitos entre os usuários da água, em função da demanda pelo uso. A região apresenta a maior evapotranspiração do estado e oito meses de deficiência hídrica no solo (abril a novembro).

Estas afirmações também são corroboradas pelo estudo de Fialho (2016) e da Companhia Ambiental do Estado de São Paulo (CETESB) (2013), onde ponderam que o Assentamento Estrela da Ilha está localizado no Aquífero Bauru que é constituído por rochas sedimentares do Grupo Bauru e Grupo Caiuá. Sua recarga/ abastecimento ao longo do ano é feita quase que exclusivamente por precipitação 
pluvial, o que a torna muito dependente de um bom período chuvoso.

Ademais, dados da Pesquisa sobre Qualidade de Vida, Produção e Renda dos Assentamentos da Reforma Agrária 2010 (2012) (PQRA) realizada pelo INCRA nos assentamentos brasileiros apontaram que $21,02 \%$ dos lotes não possuíam água suficiente para as tarefas diárias das famílias assentadas.

Outro problema observado durante o estudo foi com relação a perfuração desordenada de poços do tipo caipira ou cacimba, já que a maioria destes eram construídos pelos próprios assentados, que muitas vezes não tinham acompanhamento técnico, e os poços apresentavam pouca profundidade, ficando mais suscetíveis à contaminação.

Além disso, outro problema apontado pelos assentados que se propuseram a construir poços semi-artesianos com acompanhamento técnico, foi o endividamento e o comprometimento do orçamento com essa construção, posto que, se os poços construídos pelo INCRA estivessem em funcionamento não precisariam ter gasto com outro poço.

Com relação a qualidade de água do assentamento, esta foi apontada como um quesito preocupante para os assentados, pois segundo relatos eles não sabiam qual era a qualidade da água que consumiam. Alguns assentados relataram que houve coletas de amostra de água pelo INCRA em 2005, mas desconheciam os resultados das análises de água. No entanto, estudos de Fialho et al (2017), realizados no assentamento demonstraram que a água para o consumo humano estava fora dos padrões, ou seja, quando aferiu-se o pH (Potencial Hidrogeniônico que consiste num índice que indica a acidez, neutralidade ou alcalinidade de um meio) as amostras de água apresentaram valores que variavam entre 5,1 a 7,6 e que os limites de tolerância estabelecidos na legislação brasileira estão entre 6,0 e 9,5, ou seja, em alguns lotes a água se apresentava ligeiramente ácida.

Em relação à turbidez da água, de acordo a Portaria do Ministério da Saúde $\mathrm{n}^{\circ} 2.914$ de 2011, para consumo humano não deve ultrapassar a 5,0 Unidade de Turbidez (uT) (BRASIL, 2011). Todavia, 33\% dos lotes pesquisados apresentaram valores acima do estabelecido pela referida legislação, com valores variando entre 0 a 16,0 uT. Com relação aos parâmetros microbiológicos para coliformes termo tolerantes e/ou Escherichia coli, as análises microbiológicas apontaram que $5 \%$ dos lotes tinham a presença desta bactéria do tipo enteroinvasora. Isto é um problema, pois são bactérias que causam infecções urinárias e, principalmente, diarreias causando riscos à saúde das pessoas e animais que consomem essa água (FIALHO, et al., 2017).

Existem diversas doenças correlacionadas a falta de saneamento, sendo elas: 
diarreias, esquistossomose, cólera, leptospirose, leishmaniose, hepatite A, febre tifoide, dengue, entre outras. Segundo o Instituto Trata Brasil (2018), a incidência de internações por doenças associadas à falta de saneamento foi de 12,46 internações por 10 mil habitantes e as despesas com internações chegaram a 99 milhões de reais por ano.

\section{Esgotamento Sanitário}

Os resultados em relação ao esgotamento sanitário revelaram que $71 \%$ dos lotes pesquisados possuíam fossa séptica, embora não seja um cenário ideal, a percentagem é significativa se compararmos aos assentamentos rurais brasileiros de modo geral, pois segundo a pesquisa INCRA/PQRA (2012), apenas 11,60\% dos lotes de assentamentos do Brasil possuía fossa séptica.

O esgoto é constituído por excretas humanas como: fezes e urina; águas provenientes de uso doméstico, comercial, industrial e por águas pluviais. Deste modo, a coleta, o afastamento, o acondicionamento e a disposição final do esgoto e das águas servidas são ações fundamentais no saneamento, pois a disposição inadequada pode disseminar doenças, que podem resultar em morbidade e mortalidade, além de contribuir para a proliferação de insetos e roedores. (CARVALHO; OLIVEIRA, 2002).

Durante a pesquisa de campo, observamos que no entorno dos domicílios havia escoamento de água a céu aberto provenientes de pias de cozinha e tanques de lavar roupa. Estas águas, por sua vez são conhecidas como “águas cinzas”, contudo não oferecem risco em potencial e não fazem parte dos efluentes sanitários.

O gerenciamento correto do esgoto em áreas rurais é de fundamental importância, pois se bem conduzido contribui diretamente na prevenção de doenças de veiculação hídrica, parasitoses intestinais, diarreias, febres e infecções que podem elevar, principalmente, à mortalidade infantil em áreas mais vulneráveis (FUNASA, 2012).

É sabido que entre a fossa e o poço é necessário ter uma distância de segurança para que não haja contaminações. Por isso, foi perguntado aos assentados qual era a distância ideal entre o poço e a fossa, 37\% disseram que a distância mínima deveria ser de 30 metros, outros $18 \%$ disseram ser de 50 metros e $15 \%$ de 40 metros. Para Lopes e Palla (2004), as fossas não devem ser construídas muito perto das moradias (para evitar mau cheiro), nem muito longe (para evitar tubulações muito longas) e a distância mínima recomendada é de pelo menos 30 metros.

Ademais, o ideal é construir a fossa ao lado do banheiro em um nível mais baixo (jusante) do terreno e longe de poços ou de qualquer outra fonte de captação de água (montante) para que não ocorram contaminações no caso de eventual vazamento 
(LOPES; PALLA, 2004).

\section{Animais Peçonhentos e Vetores}

Animais peçonhentos e insetos são os que aparecem corriqueiramente na área rural, por isso os assentados foram questionados se era frequente o aparecimento desses animais nos lotes e domicílios e $89 \%$ dos entrevistados afirmaram que sim, sendo a cobra citada por 31 vezes, aranhas 14 vezes, barbeiros 8 vezes, escorpiões e ratos 6 .

É comum em áreas rurais que trabalhadores sofram acidentes com animais peçonhentos como cobras, escorpiões, aranhas, entre outros, na maior parte das vezes o contato com estes animais é mais frequente no momento da lida de trabalho na roça. Algumas hipóteses sobre a frequência de ataque aos trabalhadores rurais estão relacionada ao fato de não utilizarem vestimentas adequadas como botas, calças e blusas compridas. Com relação às picadas desses animais e insetos, $20 \%$ disseram que já foram picados por esses tipos de animais e insetos (cobras, aranhas, barbeiros, escorpiões). O que nos chamou a atenção é que metade das ocorrências

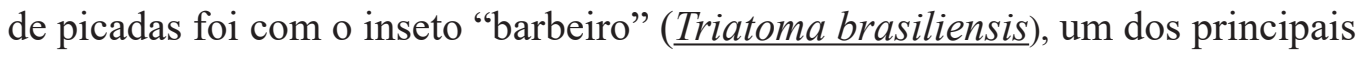
vetores da doença de Chagas, seguidos por picadas de cobras das mais diversas espécies.

O Ministério da Saúde afirma que:

"A Doença de Chagas é uma antropozoonose ocasionada pelo protozoário flagelado Trypanosoma cruzi. A doença tem duas fases: uma crônica e aguda. A estimativa é que existam entre dois e três milhões de pessoas infectadas no Brasil (BRASIL, 2014).

\section{Resíduos Sólidos}

Com relação aos resíduos sólidos, outro problema no meio rural, foi indagado aos assentados como era feito o armazenamento dos resíduos antes do destino final e $71 \%$ dos deles afirmaram que antes dos resíduos serem enterrados ou incinerados ficavam expostos próximos às moradias e a céu aberto, em contato com animais e crianças, potencializando o risco de contaminação e de acidentes.

Sobre o destino final dos resíduos sólidos, 54\% dos assentados pesquisados afirmaram que os resíduos passíveis de reciclagem como plásticos e papéis eram queimados, metais eram vendidos para ferros velhos como sucatas e os vidros eram enterrados, outros $26 \%$ afirmaram que queimavam todos os tipos de resíduos passíveis de reciclagem.

Sobre a disposição incorreta e a destinação final dos resíduos sólidos (queima ou 
enterro), Palhares e Mattei (2010) reiteram que a realidade de comunidades rurais se mostra complexa, seja pela falta de alternativas, seja por falta de políticas públicas, falta de investimento público, deixando a cargo das comunidades o seu destino.

Relatos durante a pesquisa evidenciaram que a incineração de resíduos é um problema substancialmente grave no assentamento, já que, segundo alguns assentados, há anos uma ventania na época de estiagem espalhou fagulhas de fogo de resíduos que estavam sendo queimados que se espalharam pelo vento pegando fogo em várias pastagens secas, queimando a área de vários lotes, causando a morte de vários animais e prejuízos aos assentados.

Quando indagados sobre o reaproveitamento dos resíduos orgânicos, 80\% dos entrevistados destinavam os resíduos orgânicos para alimentação dos animais (galinhas, porcos, cachorros).

Em relação à coleta seletiva de lixo, 100\% dos assentados pesquisados responderam não haver esse tipo de serviço prestado pela prefeitura. O que ocorria era que muitos assentados levavam seus próprios resíduos para o município de Ilha Solteira para serem destinados à reciclagem, principalmente os assentados cujo lote estava mais próximo do município.

Dados do IBGE (2013), reiteram que houve melhora significativa na coleta de lixo em áreas rurais, entre os Censos de 2000 e 2010, passando de 13,3\% para $26,0 \%$ os domicílios assistidos. Este dado pode ser considerado um avanço no período de uma década, mas ainda está longe do ideal.

Diante deste contexto, é importante salientar a promulgação da Política Nacional de Resíduos Sólidos (PNRS), lei n $\mathrm{n}^{\mathrm{1}}$ 12.305, de 2 de agosto de 2010 que foi um avanço em relação às políticas públicas sobre resíduos sólidos no país, contudo a mesma não avançou em relação a esta problemática no meio rural, tendo apenas citado que é preciso cuidar dos resíduos sólidos em áreas rurais, todavia não aponta alternativas, nem soluções e os prazos para o avanço e melhoria deste problema nas áreas rurais só se prorrogam e não se efetivam (BRASIL, 2011).

Segundo relatos dos assentados, na época do acampamento à beira da estrada havia um caminhão de lixo da prefeitura que coletava os resíduos semanalmente, mas a partir do momento que tomaram posse da terra não tiveram mais este serviço à disposição.

Em relação à percepção dos assentados sobre a temática dos resíduos, muitos relataram que a maior preocupação foi a proliferação de doenças na comunidade como: dengue, febres diversas, problemas respiratórios causados pela queima de resíduos, verminoses e diarreias. Em segundo lugar, apareceram os problemas ambientais como poluição do ar, contaminação da água e do lençol freático. 
De acordo com as observações de Moreira (2010) em estudo realizado na mesma área, para os assentados, essa atitude de queimar e/ou enterrar no lote seus resíduos sólidos prejudica o ambiente e contribui para a diminuição da qualidade de vida, uma vez que, o lixo, antes de ser queimado ou enterrado, permanece por um tempo considerável jogado no terreno (podendo ser ingerido por animais como: boi, cachorro, porco, galinha), e também nos corpos d'água e matas ciliares, trazendo doenças e animais indesejáveis. Mesmo assumindo que as práticas utilizadas para a deposição do lixo não são as mais corretas, tais famílias revelaram uma consciência quanto aos riscos e impactos que tais ações acarretam em seu próprio ambiente e à própria saúde.

Quando indagados sobre o conhecimento de alguma técnica de reaproveitamento de resíduos sólidos, 34\% dos entrevistados afirmaram conhecer alguma técnica, sendo a mais citada a compostagem. No entanto, em observações realizadas em campo, constatamos que nenhum dos lotes visitados realizava essa técnica.

A colheita de determinadas culturas deixa no solo a conhecida "palhada" que são restos vegetais e a maioria dos assentados entrevistados (94\%) deixavam a palhada no próprio solo para ser incorporada ao longo do tempo, contribuindo para a melhoria do solo.

A incorporação dos resíduos agrícolas é importante ferramenta para a conservação do solo e para o desenvolvimento da planta. Resíduos de cultura na superfície do solo é uma prática benéfica para melhorar as propriedades edafológicas, devido ao efeito na conservação do solo e água, regime térmico, atividade da fauna, e incremento no conteúdo de gás carbônico do solo (SILVA; MIELNICZUK, 1997).

Por fim, os assentados foram questionados sobre quais seriam soluções viáveis para o problema do saneamento no assentamento, muitos relataram que seria primordial um trabalho de Educação Ambiental que focasse a conscientização e melhores informações. Outro ponto citado foi a criação de um programa municipal de coleta seletiva que contemplasse o assentamento, já que o mesmo se localizava ao lado da área urbana. Além disso, os assentados também citaram a importância do serviço de Assistência Técnica e Extensão Rural (ATER) como catalisador de programas, projetos socioambientais que trabalhassem a temática tão cara aos assentados (as).

\section{CONSIDERAÇÕES FINAIS}

Concluímos que o assentamento Estrela da Ilha é um pequeno retrato dos assentamentos do país e, sobretudo, da realidade das propriedades rurais no que concerne ao saneamento básico. Esta pequena comunidade ilustra, consideravelmente, 
a histórica falta de investimento e interesse público em promover ações e políticas públicas para a saúde e a qualidade de vida das populações rurais.

As fragilidades e preocupação dos assentados com relação ao saneamento são evidentes, desde a quantidade e qualidade da água, o silêncio das instituições sobre este tema, o frequente aparecimento de animais e insetos peçonhentos e causadores de doenças, a incineração dos resíduos sólidos, o risco desse procedimento, a falta de coleta seletiva no assentamento, mesmo estando localizado na divisa da zona urbana de Ilha Solteira.

Os assentados percebem, têm conscientização e se sensibilizam com a qualidade do meio em que vivem. Os assentados reivindicam como possível solução do problema um programa e/ou projeto de educação ambiental com ênfase em informação e conhecimento sobre a questão ambiental no assentamento, um serviço de ATER mais eficiente e um programa municipal de coleta seletiva de lixo por parte da prefeitura municipal, ações cujo objetivando é alcançar o desenvolvimento rural sustentável.

É nesse sentido que levantamos algumas reflexões sobre o estudo em questão. Inicialmente, a importância de se conhecer a realidade das comunidades rurais brasileiras, em especial, os assentamentos de reforma agrária que foram espaços conquistados e se constituem em espaços de busca por um novo ordenamento fundiário no país contra a histórica concentração de terras.

Outra reflexão cabível refere-se à política de reforma agrária e suas contradições, a conquista da terra pelos assentados, na maioria das vezes ocorre por meio de muita luta e conflitos, violência. Quando o assentamento é constituído novas reivindicações se tornam realidade, onde a população assentada luta por auxílios, programas que garantam infraestrutura mínima para o lote, que passa pela moradia, estrutura sanitária, acesso a políticas públicas para subsidiar a produção e comercialização.

Em se tratando de assentamentos rurais, os projetos de reforma agrária precisam contemplar, em primeiro lugar, infraestrutura básica e digna a seus beneficiários. Para além disso, a questão do saneamento precisa atender às especificações geográficas, demográficas, culturais, sociais, econômicas que o meio rural demanda.

As políticas públicas voltadas à agricultura familiar e, em especial, aos assentamentos rurais necessitam dialogar e criar ligações com outras políticas públicas, seja de saúde, de educação, de assistência social, de meio ambiente, entre outras, e em todas as esferas, seja federal, estadual e municipal através de parcerias a fim de preencher lacunas socioeconômicas e estruturais insistentes e históricas almejando a equidade social e qualidade socioambiental do meio rural 
em que se insere.

\section{REFERÊNCIAS}

BERGAMASCO, S.M.P.P., NORDER, L.A.C. O que são assentamentos rurais. São Paulo: Brasiliense, 1996. 88p. (Col. Primeiros Passos, 301).

BIERNACKI, P.; WALDORF, D. Snowball sampling: problems and techniques of chain referral sampling. Sociological Methods \& Research, San Francisco, v.10, n. 2, p.141-163, nov. 1981.

BRASIL, Política Nacional de Resíduos Sólidos. Disponível em: http://www. planalto.gov.br/ccivil_03/_ato2007-2010/2010/lei/112305.htm Acesso em: 28 set. 2011.

BRASIL. Ministério da Saúde. Portaria no 2.914, de 12 de Dezembro de 2011. Dispõe sobre os procedimentos de controle e de vigilância da qualidade da água para consumo humano e seu padrão de potabilidade. Disponível em: http://bvsms. saude.gov.br/bvs/saudelegis/gm/2011/prt2914_12_12_2011.html Acesso em: 10 abr. 2018.

BRASIL. Lei $\mathbf{n}^{0}$ 11.445, de 5 de Janeiro de 2007. Disponível em: http://www. planalto.gov.br/ccivil_03/_ato2007-2010/2007/lei/111445.htm Acesso em: 23 mar. 2013.

BRASIL. IBGE-Instituto Brasileiro de Geografia e Estatística. IBGE. Lixo équeimado em 58\% dos domicílios rurais. Sala deImprensa. Disponívelem:http://saladeimprensa. ibge.gov.br/noticias?view=noticia\&id=1\&busca=1\&idnoticia=2017 . Acesso em: 12 mar. 2013.

BRASIL. Ministério das Cidades. Secretaria Nacional de Saneamento Ambiental. PLANSAB - Plano Nacional de Saneamento Básico. Mais Saúde com Qualidade de Vida e Cidadania. Brasília: SNSA, 2014. Disponível em: http://www.funasa. gov.br/documents/20182/21862/sustentar_publicacao/915644d2-fb28-409c-a 7cac3cff0e59e98 . Acesso em: 20 nov. 2019.

BRASIL. Doença de Chagas. Disponível em: portal.saude.gov.br. Acesso em: 03 nov. 2014. 
BRASIL, Secretaria Nacional de Saneamento Ambiental. Sistema Nacional de Informações sobre Saneamento: diagnóstico dos serviços de água e esgotos -2014. Brasília, DF: Ministério das Cidades, 2016. Disponível em: http://www. snis.gov.br Acesso em: 20 mar. 2017.

CARVALHO, A. R. de; OLIVEIRA, M. V. C. Princípios básicos do saneamento do meio. 9. ed. São Paulo: SENAC, 2007.

CETESB. Qualidade das águas subterrâneas do Estado de São Paulo 2010-2012. São Paulo: Série Relatórios ISSN/0103-4103, 242 p, 2013. Disponível em: http:// cetesb.sp.gov.br/aguas-subterraneas/publicacoes-e-relatorios/ . Acesso em: 11 set. 2016.

FIALHO, J. M. Avaliação microbiológica da água consumida numa área rural de Ilha Solteira, Estado de São Paulo. 2016. 93 f. Dissertação (Mestrado) - Curso de Programa de Pós-graduação em Agronomia, Defers, UNESP, Ilha Solteira, 2016. Cap. 1.

FIALHO, J. M. ; LEITE, M. A. ; PIÃO, A. C. S. ; DORNFELD, C. B. ; ALVES PRADO, H. F. Avaliação microbiológica da água consumida por uma população rural de Ilha Solteira - São Paulo. Revista Brasileira de Engenharia de Biossistemas (UNICAMP), v. 11, p. 273-286, 2017. Disponível em: http://seer. tupa.unesp.br/index.php/BIOENG/article/view/550 . Acesso em: 10 de mar. 2018.

FUNASA. Fundação Nacional de Saúde. Resíduos Sólidos e a Saúde da Comunidade. 1. ed. Rev. Brasília: Fundação Nacional de Saúde, 44p. 2009. Disponível em: http://pesquisa.bvsalud.org/bvsms/resource/pt/mis-38902 . Acesso em 30 de mai. 2018.

FUNASA - Fundação Nacional de Saúde. Funasa (Org.). Saneamento Rural. Ministério da Saúde. Disponível em: http://www.funasa.gov.br/site/engenhariade-saude-publica-2/saneamento-rural/ . Acesso em: 03 dez. 2012

GIL, A. C. Métodos e técnicas de pesquisa em educação ambiental. In: PHILIPPI JUNIOR, A.; PELICIONI, M. C. F. (Org.). Educação ambiental e sustentabilidade. Barueri: Manole, 2005. p. 577-598. 
HERNANDEZ, F.B.T.; SOUZA, S.A.V.; ZOCOLER, J.L.; FRIZZONE, J.A. Simulação e efeito de veranicos em culturas desenvolvidas na região de Palmeira d'Oeste, Estado de São Paulo. Engenharia Agrícola, v. 23, n. 1, p. 21-30, 2003.

IBGE. Censo Demográfico 2010. Disponível em: https://censo2010.ibge.gov.br/. Acesso em:20 nov. 2018.

IBGE. Pesquisa Nacional por Amostra de Domicílios - PNAD 2014 - microdados da amostra. 2015.

IBGE, Síntese de Indicadores Sociais: uma análise das condições de vida da população brasileira: 2016, Rio de Janeiro : IBGE, 2016, 146p. Disponível em: https://biblioteca.ibge.gov.br/visualizacao/livros/liv98965.pdf Acesso em: 20 mar. 2018.

INSTITUTO NACIONAL DE COLONIZAÇÃO E REFORMA AGRÁRIA. INCRA (Org.). Pesquisa Sobre a Qualidade de Vida, Produção e Renda dos Assentamentos da Reforma Agrária. Brasília Disponível em: http://www.incra. gov.br/index.php/reforma-agraria-2/questao-agraria/numeros-da-reforma-agraria/ file/1152-pesquisa-qualidade-de-vida-nos-assentamentos-2010 . Acesso em 08 nov. 2012.

INSTITUTO TRATA BRASIL (São Paulo). Instituto Trata Brasil. Internações de doenças por veiculação hídrica no Brasil. 2018. Disponível em: http://www. tratabrasil.org.br/blog/2019/05/21/internacoes-de-doencas-por-veiculacao-hidricano-brasil/. Acesso em: 20 fev. 2018.

INSTRUÇÃO NORMATIVA INCRA N 015, DE 30 DE MARÇO DE 2004 (2004) Disponível em: <www.incra.gov.br>. Acessado em 2014.

LOPES, L. G.; PALLA, V. L. Instrução Prática Saneamento Rural: O Esgoto e a Água Potável na Propriedade. 272. ed. CATI São Paulo: CATI, 2004. 20 p.

MINAYO, M. C. de S (Org.). Pesquisa Social: teoria, método e criatividade.18. ed. Petrópolis: Vozes, 2001.

MOREIRA, J. P. Lixo e cidadania no meio rural, uma experiência socioambiental: 
um estudo de caso do assentamento Estrela da Ilha. 2010. 29 f. Monografia (Monografia de Conclusão de Curso) - Curso de Ciências Biológicas, Departamento de Biologia e Zootecnia, UNESP, Ilha Solteira, 2010.

PALHARES, J. C. P.; MATTEI, R. M. Destino dos lixos gerados e propensão à coleta seletiva em duas comunidades rurais de Concordia-SC. Concórdia, 01 jan. 2010. p. 1-6. Disponível em: http://www.bvsde.paho.org/bvsaidis/uruguay30/ BR05387_Palhares.pdf. Acesso em: 12 mar. 2013.

SILVA, I.F. MIELNICZUK, J. Avaliação do estado de agregação do solo afetado pelo uso agrícola. Revista Brasileira de Ciência do Solo, 21:313-319, 1997.

World Health Organization (WHO) and The United Nations Children's Fund (UNICEF). (Ed.). Progress on drinking water, sanitation and hygiene: 2017 update and SDG baselines. Switzerland: JMP, 2017. 110 p. Anna Grojec. Disponível em: https://www.unicef.org/publications/index_96611.html . Acesso em: 20 fev. 2018. 